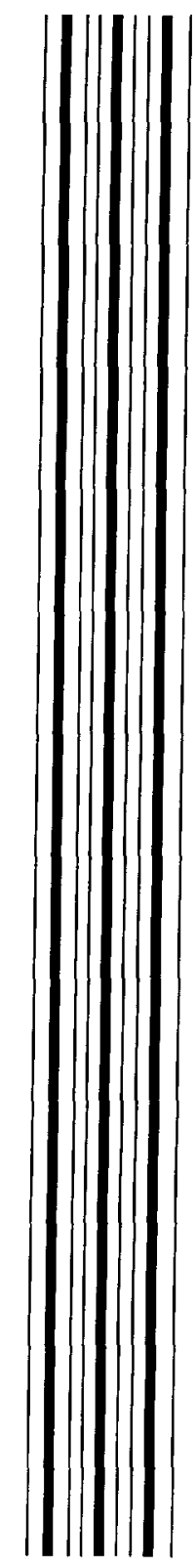

Preprint

UCRL-JC-142284

\title{
Critical Current Measurements of Large Conductors of Niobium- Titanium/Copper Cable Embedded in an Aluminum Stabilizer
}

\author{
R. P. Walsh, J. R. Miller, T. G. O'Conner
}

This article was submitted to

U.S. Department of Energy

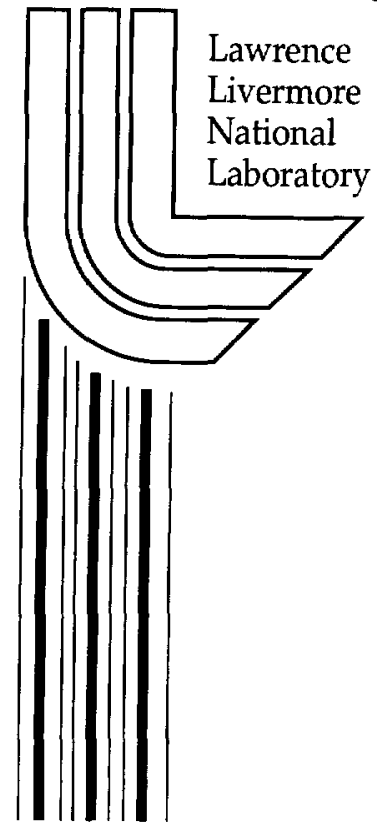

1998 Applied Superconductivity Conference, Palm Desert, CA,

September 13-18, 1998

June 1, 1999 


\section{DISCLAIMER}

This document was prepared as an account of work sponsored by an agency of the United States Government. Neither the United States Government nor the University of California nor any of their employees, makes any warranty, express or implied, or assumes any legal liability or responsibility for the accuracy, completeness, or usefulness of any information, apparatus, product, or process disclosed, or represents that its use would not infringe privately owned rights. Reference herein to any specific commercial product, process, or service by trade name, trademark, manufacturer, or otherwise, does not necessarily constitute or imply its endorsement, recommendation, or favoring by the United States Government or the University of California. The views and opinions of authors expressed herein do not necessarily state or reflect those of the United States Government or the University of California, and shall not be used for advertising or product endorsement purposes.

This is a preprint of a paper intended for publication in a journal or proceedings. Since changes may be made before publication, this preprint is made available with the understanding that it will not be cited or reproduced without the permission of the author.

This work was performed under the auspices of the United States Department of Energy by the University of California, Lawrence Livermore National Laboratory under contract No. W-7405-Eng-48.

This report has been reproduced directly from the best available copy.

Available electronically at http://www.doc.gov/bridge

Available for a processing fee to U.S. Department of Energy

And its contractors in paper from

U.S. Department of Energy

Office of Scientific and Technical Information

P.O. Box 62

Oak Ridge, TN 37831-0062

Telephone: (865) 576-8401

Facsimile: (865) 576-5728

E-mail: reports@adonis.osti.gov

Available for the sale to the public from

U.S. Department of Commerce

National Technical Information Service

5285 Port Royal Road

Springfield, VA 22161

Telephone: (800) 553-6847

Facsimile: (703) 605-6900

E-mail: orders@ntis.fedworld.gov

Online ordering: http://www.ntis.gov/ordering.htm

OR

Lawrence Livermore National Laboratory

Technical Information Department's Digital Library

http://www.llnl.gov/tid/Library.html 


\title{
Critical Current Measurements on Large Conductors of Niobium- Titanium/Copper Cable Embedded in an Aluminum Stabilizer
}

\author{
R. P. Walsh and J. R. Miller \\ National High Magnetic Field Laboratory, Tallahassee, FL 32306 \\ T. G. O'Connor \\ Lawrence Livermore National Laboratory, Livermore, CA
}

\begin{abstract}
Insertion of a flat, Rutherford type, cable of NbTi/Cu composite strands into a rectangular profile of high purity aluminum is an established method of superconductor fabrication for certain applications. Although this processing scheme has numerous advantages it produces a composite material whose properties are difficult to predict with precision. The $B A B A R$ detector magnet currently being tested at the Stanford Linear Accelerator Center, uses high-purity aluminum stabilized superconducting cable. The performance of the superconductor is dependent on the quality of the fabrication of the composite conductor. Here we present measurements of the critical transport current of BABAR production grade conductors up to $10 \mathrm{kA}$, and at fields up to $10 \mathrm{~T}$. Data are related to production variables, compared to estimates from simple models, and evaluated with respect to design specifications.
\end{abstract}

\section{INTRODUCTION}

A new detector called $B A B A R$, has been designed and constructed at the Stanford Linear Accelerator Center (SLAC). The superconducting magnet sub-systems use highpurity aluminum (HP-Al) stabilized composite superconducting cables. To verify performance, tests of the current transport characteristics were performed on full-scale conductors at the National High Magnetic Field Laboratory (NHMFL). The large size and high current carrying capability of the conductor is well suited for characterization in the $13 \mathrm{~T}$ split-solenoid test station of NHMFL's Large Magnet Component Test Facility. The test facility allows testing of the conductors under simulated operating conditions. These tests verified conductor performance and have provided unique data to aid in the understanding of the characteristics of HP-Al stabilized composite conductors.

\section{BACKGROUND}

The design of HP-Al stabilized conductors must take into account conductor degradation due to processing variables such as cabling, roll forming, and co-extrusion, as well as the integrity of the stabilizer/superconductor interface bond. The critical current of the as-fabricated superconductor has been measured previously on samples extracted from production grade conductors by chemically etching away the aluminum matrix [1]. The prior test results of the cable showed that the critical current exceeds the design critical current

Manuscript received Sept. 14, 1998.

This work was supported in part by NSF Grant No. 9527035 and in part by Stanford Linear Accelerator Center. specification: $\mathrm{Ic}(\mathrm{B}=2.5 \mathrm{~T} ; \mathrm{T}=4.2 \mathrm{~K})=12.68 \mathrm{kA}$. Th lowest critical current measurement on short samples wa $14.25 \mathrm{kA}$. The tests reported here, of the as-fabricater composite conductor samples, were performed to eliminat concerns about the influence of sample preparation and tes methodology.

\section{CONDUCTOR DESCRIPTION}

The conductor is composed of a $\mathrm{NbTi} / \mathrm{Cu}$ fla superconducting cable (Rutherford Cable) that is embeddec in a rectangular channel of high purity aluminum (HP-Al) using a co-extrusion process. In order to have a fiek homogeneity specified by the BABAR experiment, the curren density in the winding is graded: lower in the central region and higher at the ends. The gradation is obtained by usint conductors of two different thickness: $8.4 \mathrm{~mm}$ for the centra region and $5 \mathrm{~mm}$ for the ends. Both $20 \mathrm{~mm}$ wide conductor: are composed of a 16 strand Rutherford cable stabilized by pure aluminum. Table I describes the strands, the Rutherforc cable and the full-scale conductor characteristics. Thi conductors are supplied by Europa Metalli (Fornaci di Barg: -Italy). The co-extrusion processes were carried out a ALCATEL SWISS CABLE under assistance of ETH Zurich.

\section{TEST PROCEDURE}

The tests are conducted using the $13 \mathrm{~T}$ split-solenoid tes station of NHMFL's Large Magnet Component Test Facility The key components of the test station are the split-solenoir superconducting magnet $(150 \mathrm{~mm}$ bore, $30 \mathrm{~mm}$ by $70 \mathrm{mn}$ radial access port, $100 \mathrm{~mm}$ length uniform field region) an the laboratory's main DC power supply configured to delive $200 \mathrm{~V}$ and $12 \mathrm{kA}$. The split-solenoid magnet test facility $\mathrm{i}$ described elsewhere [2]. Four separate conductors from fou production lots were tested. The analysis procedure used to interpret the data for only one sample (no.7) at one applie field $(8 \mathrm{~T})$ will be reported here.

Straight conductor lengths (approx. 900mm long) fron production lot material are bent at mid-length around : mandrel to produce a hairpin sample. The sample is inserte into the $30 \mathrm{~mm}$ by $70 \mathrm{~mm}$ radial access port of the spli solenoid magnet (Fig. 1); the orientation is such that th applied magnetic field is perpendicular to the sample': current flow and parallel to the wide face of the conductor The samples are attached to a structural/electrically insulatin sample holder and current leads are soldered to the top end of the sample. The current flow through the sample $i$ 
TABLE I

SUMMARY OF SPECIFICATION FOR STRANDS, RUTHERFORD AND FULL CONDUCTOR

\begin{tabular}{lll}
\hline Component & Characteristic & Value \\
\hline Strand & NbTi & Nb 46.5 $+1-1.5 \mathrm{wt} \% \mathrm{Ti}$ \\
& Filament size & $<40 \mu \mathrm{m}$ \\
Twist pitch & $25 \mathrm{~mm}$ \\
Cu/NbTi ratio & $>1.1$ \\
RRR & Final $>100$ \\
& Wire diameter & $0.8 \mathrm{~mm} \pm 0.005$ \\
Rutherford & Transposition pitch & $<90 \mathrm{~mm}$ \\
& Number of strands & 16 \\
Final size & $1.4 \times 6.4 \mathrm{~mm} 2$ \\
Conductor & Al-RRR & $\sim 1500$ \\
& Dimensions: & $(4.93 \times 20) \pm 0.02 \mathrm{~mm}$ \\
& Thin conductor & $(8.49 \times 20) \pm 0.02 \mathrm{~mm}$ \\
& Thick conductor & $>20 \mathrm{MPa}$ \\
& Rutherford-Al bonding & $23.5: 1.1: 1$ \\
& Al/Cu/NbTi ratio: & $42.4: 1.1: 1$ \\
& Thin conductor & $>0.2 \mathrm{~mm}$ \\
\hline
\end{tabular}

directed such that Lorentz forces tend to compress the sample onto the G-10 sample holder. The current is supplied through $12 \mathrm{kA}$ vapor cooled leads to flexible NbTi cables with copper block terminations that are soldered directly to the aluminum jacketed sample.

The relatively short, U-shaped sample is positioned in the magnet such that the $U$ shape of the sample is in the high field region. The $4.2 \mathrm{~K}$ tests are performed with a constant background field (for each data set) while the test sample current is ramped monotonically (Rate $=50 \mathrm{~A} / \mathrm{s}$ ) and sample voltage (tap spacing is $100 \mathrm{~mm}$ ) is recorded.

\section{TEST RESULTS}

The results are twofold: first the tests confirm an effective electrical joint between the HP-Al stabilizer and the superconducting cable and secondly they verify superconductor performance including both critical current and index, under simulated operating conditions.

The early portion of the typical voltage versus current trace show the inherent characteristics due to the current distribution in the composite conductor (Fig. 2). When the superconductor to resistive transition occurs, power-law dependence is observed. The detailed shape of the trace

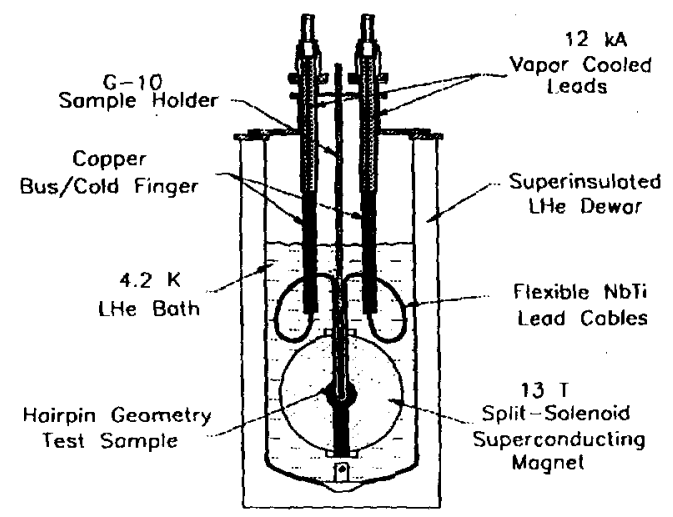

Fig. 1. Sectional schematic of $13 \mathrm{~T}$ magnet showing test sample position. depends upon intrinsic superconductor performance, selffield effects, and current sharing by the HP-Al stabilizer, which can be modeled as follows. Measurements of $V$ vs. $i$ for single wires in an external applied field $B_{a}$ are observed to have power law dependence and the specification of the critical current $i_{c}\left(B_{a}\right)$ is done consistently with a voltage criterion $V_{0}$ and an index $n$ according to:

$V(i)=V_{0}\left[\frac{i}{i_{c}\left(B_{a}\right)}\right]^{n}$,

If $N$ wires are combined in a cable, a simplified expectation of the $V-I$ characteristic might be

$V(I)=V_{0}\left[\frac{I}{I_{c}\left(B_{a}\right)}\right]^{n}$,

where

$I_{c}\left(B_{a}\right)=N i_{c}\left(B_{a}\right)$.

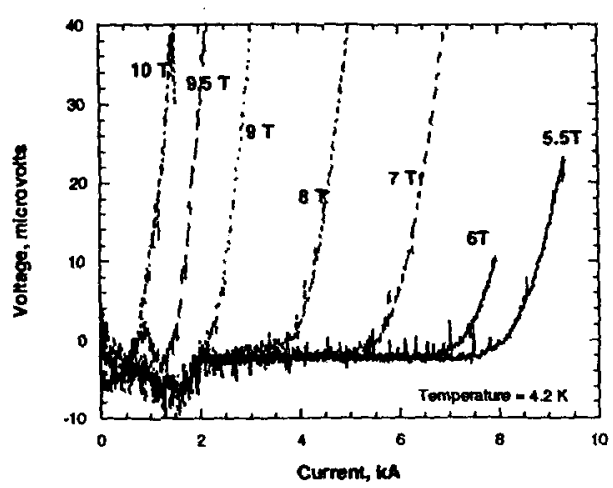

Fig. 2. Voltage vs current data at various applied fields for tests of sample 7. 
However, the appropriate field $B$, to be considered in the evaluation of a large, high-current conductor is the worstcase combination of applied field $B_{a}$ and maximum self field $B_{s}$ i.e.

$$
B_{t}=B_{a}+B_{s}(I),
$$

which modifies the critical-current criterion according to [3]

$$
I_{c}\left(B_{t}\right)=I_{c}\left(B_{a}\right)\left(\frac{B_{a}}{B_{t}}\right)^{0.4}\left[\frac{B_{c 2}(T)-B_{t}}{B_{c 2}(T)-B_{a}}\right] .
$$

The self-field for the present conductors has been estimated to be approximately

$$
B_{s}=0.084 \times 10^{-3} I_{s c},
$$

where $I_{\mathrm{s}}$ is the current inside the superconductor cable. The critical field at $4.2 \mathrm{~K}$ was taken to be about $10.4 \mathrm{~T}$.

In the case of conductors with a large fraction of highconductivity stabilizer shunting the superconductor, the transfer of a portion of the total current to the stabilizer according to the following also modifies the trace:

$$
\begin{aligned}
& V_{s c}=V_{0}\left[\frac{I_{s c}}{I_{c}\left(B_{t}\right)}\right]^{n}=V_{s t a b}=V\left(I_{t}\right), \\
& I_{s t a b}=\frac{V_{s t a b}}{R_{s t a b}},
\end{aligned}
$$

and

$$
I_{t}=I_{s c}+I_{s t a b} .
$$

The above discussion defines a fitting procedure in which $i_{c}\left(B_{a}\right)$ and $n$ are the fitting parameters, thus giving a direct comparison between the measured V.I traces for the cable with stabilizer and those that might be expected on individual strands.

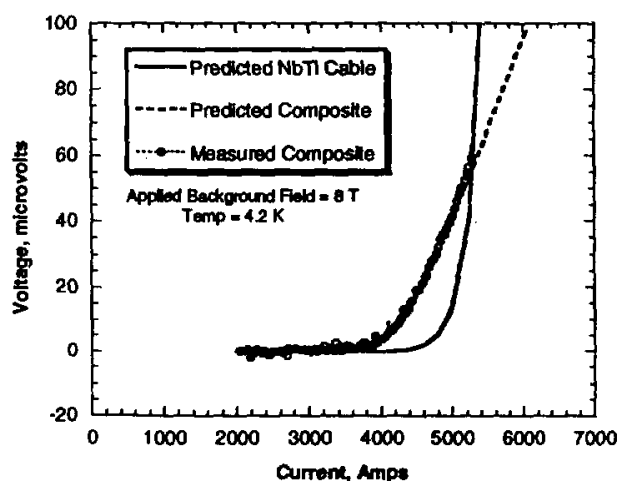

Fig. 3. The relationship between measured data and predicted for sample 7 at applied background field of $8 \mathrm{~T}$.
Fig. 3 shows the excellent agreement between the test data of the full-scale conductor at $8 \mathrm{~T}$, and the curve generated by the predictive equation for the full-scale conductor. The good agreement between measured and predicted data is observed for all the tests, establishing confidence that the effects of the $\mathrm{HP}-\mathrm{Al}$ and self-field have been quantified. Also plotted in Fig. 3 is a curve of the expected performance of the Rutherford cable without HP-Al stabilizer. The curve is predicted using the measured data and eliminating the now quantified effects of the HP-Al and the self-field. This is the defining curve that provides the critical current and index of the as-processed Rutherford cable. Applying a $1 \mathrm{e}-4 \mathrm{v} / \mathrm{m}$ voltage criterion to the curve results in a critical current of $4.45 \mathrm{kA}$ at $8 \mathrm{~T}$. The index of the cable is relatively low (23) for $\mathrm{NbTi}$ and may need to be studied more carefully tc determine the reason for this. For reference purposes the results of the test on sample 7 are extrapolated to the BABAR magnet design operating field of $2.5 \mathrm{~T}$. The extrapolation is based on well-known empirical relationships for $\mathrm{NbTi}$ [3] The extrapolation yields a relatively high critical current ( 2 : $\mathrm{kA}$ ) for the superconductor at $2.5 \mathrm{~T}$. This value exceeds the prior estimate $(14.2 \mathrm{kA})$ for the conductor, obtained in shor: sample tests [1].

\section{CONCLUSIONS}

Full-scale production-grade conductors for the BABAF detector magnet have been successfully tested unde? simulated service conditions to provide engineering performance data. The critical current of the cable show: little degradation due to processing.

Analysis of the data demonstrates that conducto performance is consistent with our understanding and the properties of a HP-Al stabilized conductor are predictabl. with a high degree of certainty.

Based on our understanding of the present data fo stabilized composite conductors, we suggest that curren margins for the magnet are even higher than might $b$ expected from previous tests of extracted cables.

\section{ACKNOWLEDGEMENTS}

The authors would like to thank J. Kenney of NHMFL fo his technical expertise in sample preparation and G. Wenc for his assistance with the tests.

\section{REFERENCES}

[1] P. Fabbricatore, S. Farinon, R. Musenich, C. Priano, T. G. O'Connor, I A. Bell, W. Burgess, W. Craddock, R. Penco, and P. Valente, "TI superconducting solenoid for the BABAR experiment at PEP-II in SLAC IEEE Transactions on Magnetics, vol.

[2] L.T. Summers, R. P. Walsh, and J. R. Miller, "A facility for th characterization of the critical current of superconductors as a function strain and magnetic field" IEEE Transactions on Applit Superconductivity, vol. 5 (2), pp. 1896-1899, 1995.

[3] Any of a number of commonly used relations allow quite adequa projections of $\mathrm{NbTi}$ critical current vs field and temperature. We choose use one from the computer program GANDALF, an analysis code for forc cooled conductors marketed by Cryosoft, 5, rue de la Belette, F-017 THOIRY, France. 